\title{
Regimes with periodical pressure pulsation in Francis draft tube
}

\author{
Ivan Litvinov", Evgeny Gorelikov, and Sergey Shtork \\ Kutateladze Institute of Thermophysics, SB RAS, Novosibirsk, Russia
}

\begin{abstract}
The paper reports on results of the experimental study of flow and pressure pulsations in a laboratory model of the draft tube of Francis99 hydro turbine over a broad range of operating regimes. A novelty is the rapid prototyping and 3-d printing of the inflow swirl generators that makes it possible to acquire rapidly a large amount of experimental data for a variety of designs and operating conditions. The frequency characteristics of flow and the phase-average pressure distribution in draft tube cone have been measured with the aid of special acoustic sensors.
\end{abstract}

\section{Introduction}

Expansion of the range of sustainable and reliable operating regimes of the hydro turbine, including those at nonoptimal conditions is an important task of the hydro power industry. Often at nonoptimal operation, especially for the Francis turbine, the flow entering into the draft tube (DT) keeps significant residual swirling intensity. Some peculiar phenomena of vortex instability have appeared in the decelerating swirl flow, which are named as vortex breakdown and precessing vortex core (PVC) or precessing vortex "rope". The effects associated with the transformation of an axisymmetric swirl flow in one or more precessing vortexes causes dangerous periodic vibrations on the draft tube walls $[1,2]$.

In present paper we report on approach to studying regimes with vortex instability and high level of pressure pulsations using «rapid» experimental methods and the air model of hydro turbine draft tube. During the experiments pressure pulsations on draft tube walls have been studied with acoustic sensors for different regimes (about 900 regimes) simulating different loadings of the turbine generator. Regimes with high level of pressure pulsations and PVC formation were identified. Further detailed studies provide new information on unsteady vortex structures under nonoptimal regimes in hydro turbine draft tube.

\section{Experimental setup}

Figure 1 shows sketch of the test section which includes a scale-down geometrical model of the Francis-99 draft tube [3] with an inlet diameter $D=100 \mathrm{~mm}$ and a special device for generating the inflow into the conical part of the draft tube. Air at atmospheric pressure was

*Corresponding author: litvinov@itp.nsc.ru 
used as the working medium [4]. This allows reducing significantly the cost and simplify the fabrication of the working channel based e.g. on the available plastic materials. To generate the required flow distribution at the inlet to the draft tube, a pair of swirlers was used: a stationary swirler, acting as guide vanes and a rotary one is an analog of the turbine runner, as in $[5,6]$. However, in contrast to those studies, which used a freely rotating impeller, here the rotor speed is controlled by the servomotor at a specified frequency. The geometry of the swirlers was determined by numerical simulation, targeted to reproduce best the velocity distributions at the draft tube inlet for different operating modes of a radial-axial Francis hydro turbine [7, 8]. On the basis of the calculated geometry, the physical models of the swirler pairs were fabricated using 3-d printing. The experimental setup included a computer-aided system for controlling the airflow and rotation frequency of the rotor. During the experiments, the pressure pulsation levels at the walls of the draft tube model were recorded with high-sensitivity microphones. To register distribution of pressure in draft tube cone, phase-averaged technique was applied; the special probes in the form of a thin tube of 2-mm diameter were connected to microphones as described in [9].

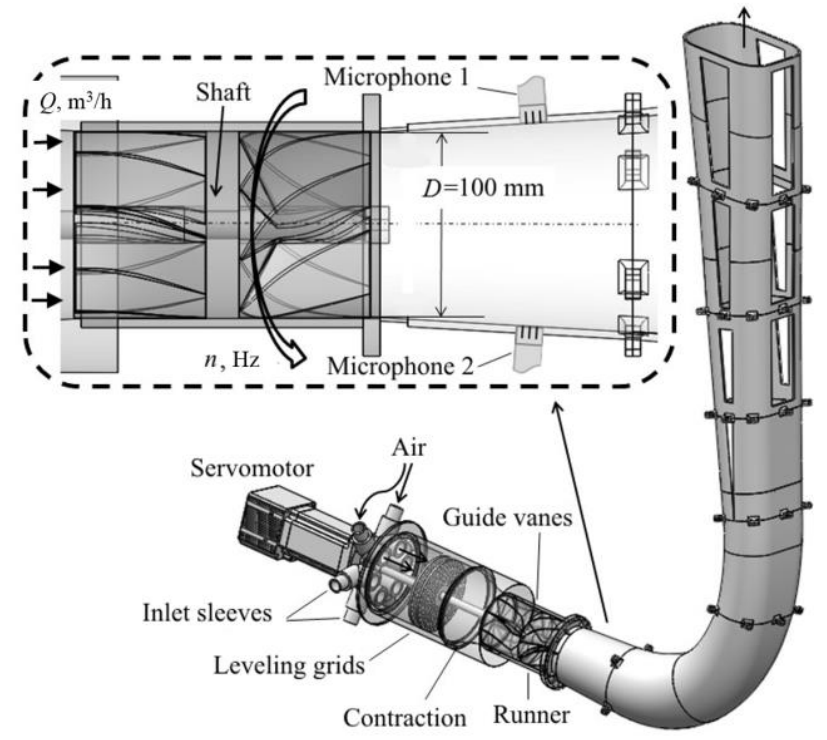

Fig. 1. Schematic of the experimental setup.

\section{Results}

Figure 2 presents sample results for the pair of swirlers, designed for optimal operating conditions (the best efficiency point - BEP), corresponding to the volumetric flow rate $Q_{c}=48.5 \mathrm{l} / \mathrm{s}$ and the runner rotation speed $n_{c}=40.5 \mathrm{~Hz}$. The plot on the left illustrates the pressure pulsation levels for almost 900 operation regimes, shown by spectral peaks obtained from the differential signals of two microphones positioned as shown in Fig.1. This method allows extracting the flow instability mode associated with the precessing vortex core (PVC) [10]. It can be seen that a departure from the BEP, for example by decreasing the flow rate below $Q_{c}$ at a fixed rotor speed $n=n_{c}$ (partial load) leads to an increase in the pulsation level. The elevated flow pulsations are caused by the PVC, precessing with a dominant frequency, which is clearly visible in the spectrum of the acoustic signal, Fig. 2(c) right. Starting from the flow rate $\mathrm{Q}=0.4 Q_{c}$ the peak with dominant frequency emerges; further at rate of $0.5 Q_{c}$ the peak amplitude reaches a maximum. When 
approaching the design condition $\left(Q_{c}\right)$ the PVC frequency disappears from the spectrum completely. The obtained amplitude (normalized by bulk velocity $U_{0}$ in the cone inlet) of the dominant frequency in pressure spectra for each value of $Q / Q_{c}$ are shown in Fig. $2 \mathrm{~b}$. From the data, it is seen that a local extremum arises $\left(Q=0.5 Q_{c}\right)$. This extremum occurs due to the formation of the precessing vortex core in the draft tube cone.
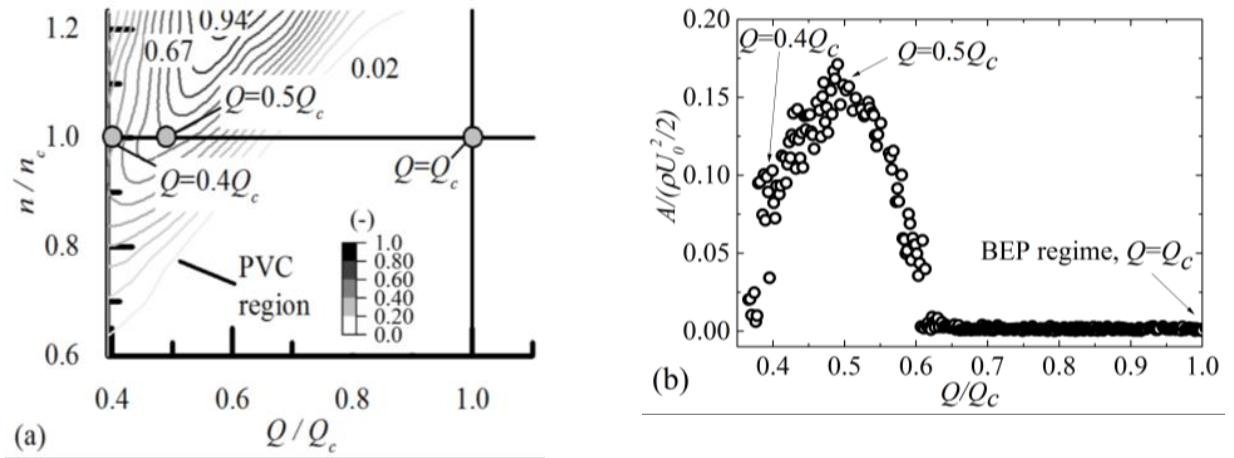

(a)
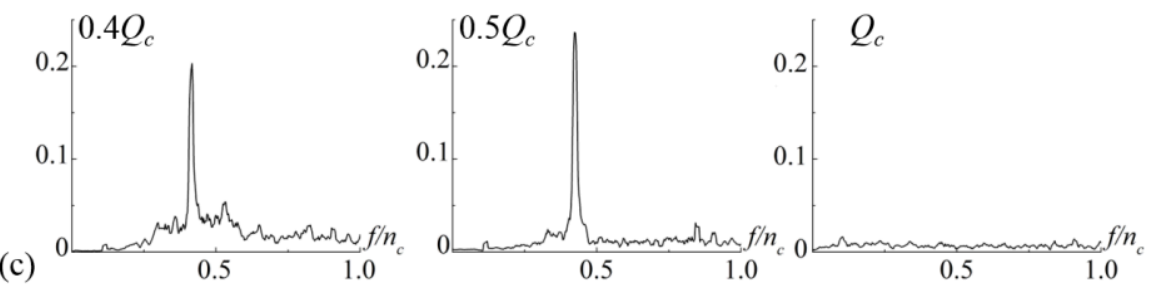

Fig. 2. Pressure pulsation level (arbitrary units) vs. regime parameters: $Q$ is the air flow; $n$ - the runner rotation speed (a); pressure pulsation distribution along the line $n=n_{c}$ (b); typical spectra: $Q=0.4 Q_{c}$, $0.5 Q_{c}, Q_{c}$ (BEP), vertical axes in arbitrary units.
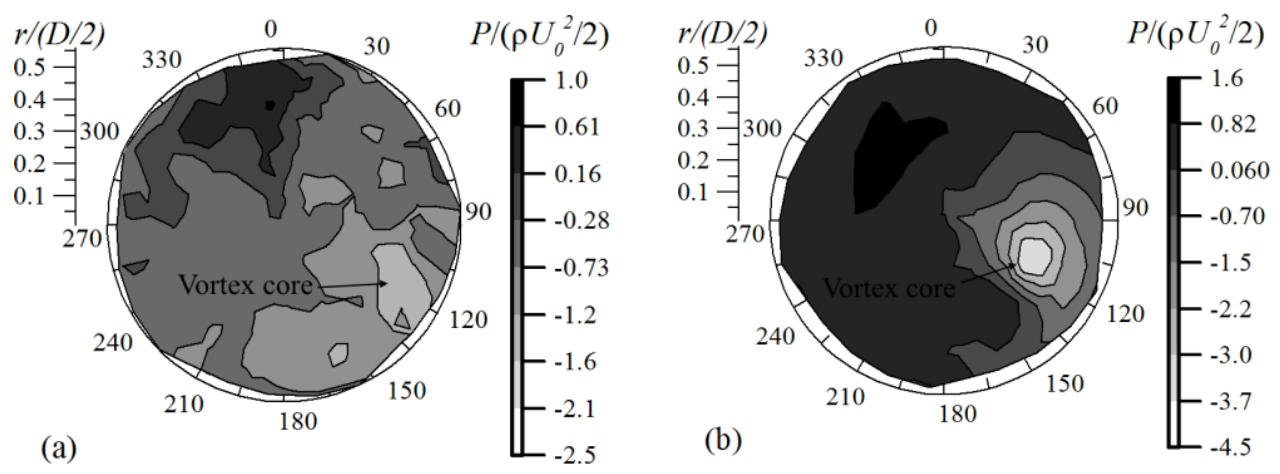

Fig. 3. Experimental phase-averaged pressure field in DT cross section (in the center of cone length): at $0.4 Q_{c}(\mathrm{a})$, at $0.5 Q_{c}(\mathrm{~b})$.

For better understanding a structure of the precessing vortex, we performed phaseaveraged experiment using two acoustic sensors [9] for two regimes $Q=0.4 Q_{c}$ and $Q=0.5 Q_{c}$ (Fig. 3). It is seen that in the cross section of the draft tube the pressure field has more than one minima for $Q=0.4 Q_{c}$. These minima correspond to the centers of two mild vortex structures. When the flow rate grows up to $Q=0.5 Q_{c}$ one powerful concentrated precessing 
vortex core is formed in the draft tube cone (Fig.3b). In the vortex core center (region with minimal pressure) the pressure depression doubled. Consequently, the intensity of pressure pulsations in the draft tube cone reaches the maximum value (Fig.2).

With further increase in flow rate, the flow swirl decreases, and a concentrated vortex after the impeller loses its intensity. The radius of vortex precession after the impeller decreases, and the intensity of pressure pulsation decreases as well. In the BEP regime $\left(Q_{\mathrm{c}}\right)$ the concentrated vortex after the impeller breaks down and phase-averaged technique is not able to catch them.

\section{Conclusions}

The paper illustrates the usefulness of the rapid prototyping of physical models for the experimental study of flow unsteadiness and emergence of the unsteady vortex structures for a variety of swirler designs and a range of operating conditions. Despite the neglect of cavitation and possible scaling effects, such results can provide insight into the effect of various design and operating parameters on the flow physics, as well as serve for verification of the numerical simulations.

The pressure measurements with sophisticated acoustic sensors confirmed that the regimes with PVC formed in draft tube cone of the hydro turbine at part load regime $(0.5$

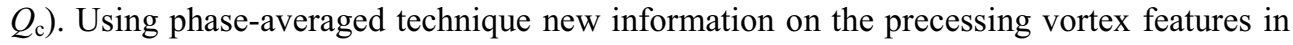
draft tube has been found.

This work was funded by the Russian Science Foundation grant No. 14-19-00487.

\section{References}

1. H.T. Falvey, Draft Tube Surges (Bureau of Reclamation, 1971)

2. R.-K. Zhang, Q.-D. Cai, J.-Z. Wu, Y.-L. Wu, S.-H. Liu, L. Zhang, Mod. Phys. Lett. B 19, 1527 (2005)

3. M. Cervantes, C.H. Trivedi, O.-G. Dahlhaug, T. Nielsen, J. Phys. Conf. Ser. 579, $011001(2015)$

4. M. Nishi, K. Yoshida, M. Yano, M. Okamoto, K. Miyagawa, S. Liu, IAHR Proceedings, Romania (2007)

5. R. F. Susan-Resiga, S. Muntean, C. Tanasa, A. Bosioc, GRoWTH Proceeding, (2008)

6. S. Skripkin, M. Tsoy, S. Shtork, K. Hanjalić, J. Hydraul. Res. 54, 450-460 (2016)

7. V. Sonin, A. Ustimenko, P. Kuibin, I. Litvinov, S. Shtork, IOP Conf. Ser. 49, 082020 (2016).

8. S. Shtork, I. Litvinov, A. Mitryakov, K. Hanjalic, EPJ Conf. Ser. 143, 02103 (2017)

9. I. Litvinov, S. Shtork, P. Kuibin, S. Alekseenko, K. Hanjalic, Int. J. Heat Fluid Flow 42, 251 (2013)

10. E. Fernandes, M. Heitor, S. Shtork, Exp. Fluids 40, 267 (2006) 